\title{
What is a Psychological Task? The Operational Pliability of "Task" in Psychological Laboratory Experimentation
}

\author{
HAZEL MORRISON \\ DURHAM UNIVERSITY \\ SHANNON MCBRIAR \\ AMSTERDAM UNIVERSITY COLLEGE \\ HILARY POWELL \\ DURHAM UNIVERSITY \\ JESSE PROUDFOOT \\ DURHAM UNIVERSITY \\ STEVEN STANLEY \\ CARDIFF UNIVERSITY \\ DES FITZGERALD \\ CARDIFF UNIVERSITY \\ FELICITY CALLARD \\ BIRKBECK, UNIVERSITY OF LONDON
}

\begin{abstract}
There has been no sustained sociological analysis of a near ubiquitous feature of psychological laboratory experimentation: the task. Yet the task is central in arranging the means by which phenomena are isolated and brought into the experimental scientist's purview. As scientific objects, states such as mind wandering and daydreaming have been made visible in experiments that draw on a (sometimes) sharp distinction between what it means to be either "on task" or "off task" - which entails a long history of what it means to have a subject attend to her task, a central aspect of the psychology experiment since its foundation. Through an analysis of qualitative interviews with research participants in studies of so-called "mind wandering," it becomes clear that task is deployed and understood in multiple ways: it is often hard to distinguish when a
\end{abstract}

'Hazel Morrison, Email: hazel.c.morrison@googlemail.com

Copyright (c) 2019 (Hazel Morrison, Shannon McBriar, Hilary Powell, Jesse Proudfoot, Steven Stanley, Des Fitzgerald, Felicity Callard). Licensed under the Creative Commons Attribution Non-commercial No Derivatives (by-nc-nd). Available at estsjournal.org. 
person is on task and when they are not; when participants reflect on their own internal states the boundedness that the concept relies upon is drawn sharply into question; and the complex spatio-temporal organization of experiences of both mind wandering and task disrupts the metaphorical structures that the scientific literature has baked into these terms. The term "operational pliability" allows us to understand how the pliability of the practice and concept of task is central to how task functions. Operational pliability offers a way of understanding how particular elements in scientific investigation are easily adaptable and at the same time are able to hold some kind of shape or form.

\section{Keywords}

experiments; mind wandering; operational pliability; psychology; qualitative interviews; task

\section{Introduction}

In a world filled with endless distraction, the question of how to stop our minds from wandering has become a pressing topic of both technoscientific and popular concern (e.g. Corballis 2015). For many, this lack of focus is a source of anxiety: "in a world awash with distractions," writes Matthew MacKinnon in Psychology Today, "all it takes is a cell phone chirp to derail us from a given task and open the door to wandering thought" (MacKinnon 2016). For others, the capacity to mind wander may have unexpected benefits: writing in the Harvard Business Review, the psychiatrist Srini Pillay (2017) argues that our capacity to "keep fixed and on task" is dependent upon building in periods of constructive daydreaming. Such divergent opinions suggest that while being "on task" is an object of shared public and scientific concern, the notion of task that sits at the heart of this anxiety is rather under-determined. On the one hand, task represents that given assignment or object to which a person ought to remain fixedly attentive. On the other hand, certain forms of constructive inattention to a given task might be beneficial, even productive. This complexity of task is also embedded in accounts of the lay terms, mind wandering and daydreaming. And this is important: mind wandering and daydreaming have not only been used to understand, scientifically, how and whether people deviate from given tasks, but have also, in the history of experimental psychology, been central to bringing the notion of task itself into a certain kind of scientific and cultural visibility.

This paper pursues the notion of task, an everyday concept that has been both widely operationalized in psychological experimentation and specifically embedded in a set of experimental concerns around the phenomena of mind wandering and daydreaming. Our central argument is that the idea of being "on" or "off" task is neither easy nor obvious in experimental psychology. Debates over how to track the process of thought, and why this matters, have deep roots in the history of the discipline, conjuring up longstanding debates over the subject's relationship to the experimental stimulus, the social situation of experimenter and experimental subject, and the wider socio-material setup of the experimental situation itself. 
Despite its wider cultural prominence, human experimental psychology is a lacuna in science and technology studies (STS). In a special issue of Theory \& Psychology, Maarten Derksen, Signe Vikkelsø and Anne Beaulieu argued that STS has tended more readily to gravitate to the harder sciences. How, they asked, would the "analytical frameworks" of STS fare when science and technology revolve "not around palpable artifacts, steely machines, and calculatory devices" but around "people and intangible phenomena" (2012: 140)? This article responds to this challenge. While STS has not exactly ignored psychology (Ashmore, Brown and Macmillan 2005; Baum 2016), articles that address psychological experimentation are rare. Where they have appeared they tend to center on the reassuringly machinic appearance of neuropsychology (Pickersgill 2011; Schüll and Zaloom 2011; Fitzgerald et al. 2014) or are embedded in investigations of how non-human organisms might model human behavior (Nelson 2013; Leonelli et al. 2014). But the tangible and intangible artifacts of mundane psychological experimentation with humans-such as setting and task instruction--remain largely opaque to STS. In this paper, we address that gap, while advancing another argument, which is that everyday elements of ordinary psychological experimentation-those considered not technically or methodologically novel, such as verbal instructions-are stubbornly central to the knowledge practices of the twenty-first century human sciences. By foregrounding the complexity that surrounds the giving and receiving of task instructions, we hope to generate renewed interest in how the human sciences carefully arrange the means by which phenomena are isolated and brought into the analyst's purview.

Empirically, we attend to the conduct of one interdisciplinary experiment on mind wandering. That experiment, inter alia, generated rich qualitative accounts of mind wandering, which were coded to parse distinct phenomenological features of different mind wandering states. As we analyzed this qualitative data, we came to realize how prominent were particular notions of task in both our and our participants' understandings of what was taking place. This paper then realizes a suspicion that a focus on task--in which experimenters work to explicate when, where, and how experimental subjects find themselves to be on task, or off task, or perhaps somewhere in between-will open up the wider conceptual and empirical stakes of this scene. We ask: (1) How, precisely, is the notion of task deployed and understood in a mind wandering experiment? (2) What does focusing on task in this specific experiment suggest about its wider operationalization in experimental psychology? (3) How might mind wandering, a mental activity that is in part defined by the degree to which one is able to stay (or not) mentally on task, enable STS scholars to analyze long-standing assumptions about the ambiguous, and deeply potent, term: task?

\section{The Operational Pliability of Task}

Given the centrality of task to the socio-material organization of experiments, it is striking that it is largely absent both in psychological writings on the discipline's methods and in historical, critical and sociological/STS analyses of the cognitive sciences. While there are discussions of better or worse task design, and of the difficulties of investigating off-task phenomena in 
disciplines wedded to cognitive tasks (Morcom and Fletcher 2007), there is virtually no extended analysis of task as an epistemological, methodological, or historical construct and/or technology in the discipline of psychology. Task emerged as psychology became an experimental and scientific discipline, and was from the start caught up in debates over who experiments, who observes, and how best to access the movements of thought (Danziger 1994). George Mandler has argued, in addressing Henry Watt's (late nineteenth-century) interest in determining the direction of thinking, that it was through Watt that the fundamental importance of the task (Aufgabe) in experiments came to scientific visibility. "[A]s the name task implies, the directive concept was an external or situational one," Mandler argues (2011: 95). He goes on to show how task shifted from being analogous to any other stimulus presented by the experimenter (and thus consciously recognized by the experimental subject, like a stimulus), to being defined as that which "gradually ... drop[ped] out of consciousness, at the same time as losing none of its effectiveness in determining the course of the reactions" (2011: 95).

Mandler's account shows us how profoundly task influences the setting into motion of the experimental subject's responses. It is also important to note how task moves between, and binds, the experimenter and the subject (or, observer, to be faithful to experimental roles as described in the late nineteenth century). This is made clear by the psychologist M.A. May who, in reflecting on die Aufgabe, noted that it comprises both "the problem set by the experimenter, the instructions given," and "the problem understood and actualized by the observer or subject" (1917; quoted in Oxford English Dictionary, no date). Conceptions of task tend, additionally, to draw psychological and racialized economic exigencies together. In the early twentieth century, the psychologist Hugo Münsterberg pointed to how "consciousness of the task to be performed has an organizing influence" on the subject's orientation to a goal, adding that "[p]edagogical experiments have ... shown exactly what influence belongs to the consciousness of the approach to the end of work; the feeling of the nearness of the close heightens the achievement, even of the fatigued subject." Münsterberg explicitly connected his psychophysical experiments "with the problems of the task and bonus system ... [of] industrial life," demonstrating the uncanny proximity between subjective responses to a task delivered in the laboratory and one prescribed on the shop floor (1913: 237-38). The task and bonus system, one of the key features of scientific management, is, in turn, ghosted by slavery. Caitlin Rosenthal, in her analysis of the intimate relationship between slavery and scientific management, argues that the task system deployed by those such as Henry Laurence Gantt and Frederick Winslow Taylor "was one of the principal methods of organizing labor under slavery" with Taylor "lamenting" the association that the word task had with the concept of slave-driving (Rosenthal 2018: 201). The activity that comprises the response to a task, in other words, cannot escape the hold that the task has in orienting the respondent's psychology and physiology as she reacts to the instruction to perform a task and moves towards that task's completion. This has implications when the task demands engaging in, and recording, states of mind, such as mind wandering, which are thought to escape close temporal monitoring by the subject who performs them.

The history of psychology from the late nineteenth century onwards is a history in which the concept and use of task is inevitably counterposed to, and vies for supremacy in relation to, 
the logic and use of introspective methods. If William James's late nineteenth-century elaboration of the stream of consciousness-a constantly moving consciousness, which is not bound by task - comprises perhaps one of the most profound investigations of the difficulties of introspective observation, then the consolidation of the task in psychology seeks precisely to transcend and displace the need for introspective methods. Robert Woodworth, for example, in an early (1899) use and definition of a psychological task, installs the task as a kind of game from which the subject "cannot escape"--prefiguring the importance of an experimental circuit that gives particular roles to the experimenter and experimental subject. Woodworth, in relation to his interest in voluntary movement, argues that "[w]e cannot tell from introspection what guides our movements," and need instead to measure the "degree of accuracy obtained under different conditions." One avoids introspection, in other words, by giving the subject "some difficult task to perform under certain conditions from which he cannot escape (much as in a game)"--and measures his relative degrees of success as one varies these external conditions (Woodworth: $1899,25)$. By the 1920s, the deployment of the term "task" - to mean an externally given task-in descriptions of psychological experimentation requires no further explication or comment (e.g. Jersild 1927). And as the twentieth-century proceeds, task becomes more and more firmly embedded within laboratory experimentation--such that experiments on "stimulus-independent thought" come to require the use of a "primary task" precisely so as to discern that which escapes the grip of that task (e.g. Antrobus 1968). Towards the end of the twentieth century, psychology witnessed a significant revivification of interest in introspective methods, in the writings of William James on consciousness, and in unconstrained thought (Jack and Roepstorff 2003). Even so, psychological experimentation--including that on mind wandering and other forms of unconstrained thought-remains today wedded to the binds of task.

Our paper extends out from this brief genealogy-showing how the concept of task, which is simultaneously so present yet so invisible in psychological practice, acts as a central methodological and conceptual arc of contemporary psychological research. Forming that arc is what we describe as task's operational pliability: with this term, we point to task's capacity to move from being that which holds the psychological setting together; to being the specific instruction that is given to the participant; to being the work that is actualized by the one receiving the instruction; to being an object that has the ability to work simultaneously through the registers of the psychological and the quotidian. Through such pliable dispositions, task does not simply denote the specific set of instructions to which the participant is expected to respond: it forms the implicit compact that binds the experimenter and experimental subject to one another.

The concept of "operational pliability" connects with a long history in STS of showing how situation and movement, of both technique and object, come to matter in science. In particular, we draw on work that has centered attention on how dynamics of mobility/immobility and stability/instability bring certain elements together, and keep others apart, within scientific practice. The early work of Bruno Latour was animated by an interest in how scientific arguments were assembled from movements of texts and other things; for Latour, the enrolment of mobile, stable, and combinable objects (maps, for example) is characteristic of scientific work; science becomes, then, a "logistical" question of moving things around, and 
bringing centers together, rather than a question of cogitation, insight, and so on (1987: 223, 237). We are also indebted to Hans-Jörg Rheinberger's account of the experimental situation-in which the "hardware" of an experimental system forms an infrastructure in which more tensile scientific objects-which Rheinberger calls "epistemic things," i.e. "halfway-concepts, no-longertechniques, and not-yet values and standards"--can make a difference (1997: 36). This tension between stability and mutability is a recurrent theme in STS work on the life sciences in particular. Peter Keating and Alberto Cambrosio, for example, in their use of the term "biomedical platform," focus on the temporary coordinating arrangements that, "hol[d] the party or the devices together for the time being" in some biomedical field or other (2000: 347). Similarly, Carrie Friese and Adele Clarke, in their work on animal models, use the concept of "transposition" to argue that what models actually do is make iterative connections between people, objects and sites (2012: 33).

Into this perhaps over-determined space we introduce operational pliability, which asks STS scholars to attend to acts of combination and temporary stabilization-acts that cross from the technical to the social, and from the subjective to the measurable. The operational pliability of task shows how a mundane technology can hold an experimental scene together--not by gathering allies or building platforms, but through the less obviously virtuous work of becoming supple and elastic. It does so by re-acquainting itself with a rather unfashionable figure in STS, the human subject, and that subject's often surprisingly mobile and biddable position in scientific space. Here, we connect with the work of the historian of psychology, Jill Morawski, who has demonstrated the centrality of psychology's "experimenter-subject system" for the production of scientific data-a system that relies on "a relationship of experimenter and subject that is intimate and mutable," and one deeply and variably embedded in cultural models of role-taking and exchange (2015: 574). Thinking task's operational pliability will thus help us to bring two things into focus: (1) the contributions of elements that are not straightforwardly objects or subjects (such as instructions) in drawing things together in scientific spaces (these elements have become difficult to discern in STS, as STS has increasingly centered attention on instruments and other material artifacts, on the one hand, and on intimate relationships, on the other); and (2) the role of human socio-cultural attributes (e.g. expectations of what a task might, or might not, be, and how it might be accomplished) in keeping the "experimenter-subject system" in motion. For an experiment to be successfully accomplished, after all, the experimental subject must be able to make some kind of connection between the psychological task she is asked to fulfill and the temporal-spatial constitution of her everyday life (an everyday life comprising, at least in part, tasks). It is precisely the operational pliability of task, we argue, that holds this scene together.

\section{Wandering Minds}

Mind wandering has lately been a site of startling growth in the cognitive sciences: Web of Science indexes three instances of mind wandering in 2006, versus 148 publications in 2018. ' Like others,

"Web of Science search specifying the topic "mind wandering" (conducted 8 March 2019). 
we are interested in understanding how scientific and social objects emerge out of a tangled field of heterogeneous phenomena (e.g. Hayward 2017). Mind wandering was initially one of many scientific and/or popular terms used to describe relatively unconstrained mental activity (e.g. stimulus-independent thought, spontaneous thought, daydreaming, and fantasy). But as Felicity Callard and colleagues have argued, its rapid rise within a number of scientific fields was aided by a considered turn to the popular term mind wandering within the psychological literature (Callard et al. 2013). This was then yoked to another emergent scientific object-the brain's "default mode network" (Callard and Margulies 2011). Neuroanatomical findings, the lay term mind wandering, and particular psychological and experimental technologies of probing helped to solidify what is now regarded as an important function of the human brain and mind.

Mind wandering thus bears traces of its status as a scientific object being "elusive and hard-won" (Daston 2000: 2). It possesses a degree of scientific coherence and legibility by dint of how a number of tools, techniques, cross-disciplinary interests, and models came together to mold, and then hold together, its heterogeneous features. As a phenomenon it can plausibly be differentiated from other ephemeral mental states and activities (such as trance) - but cannot easily be captured using standard psychological tools (which have in general shied away from introspective techniques). Indeed, psychological explorations of mind wandering cannot escape the methodological challenge of eliciting, at some point, a participant's own description of her mental state. Despite fervently held wishes to the contrary (see Ali, Lifshitz and Raz 2014), neither machines nor psychological techniques can reliably decipher the thoughts of another, and there are no robust behavioral markers of mind wandering. Nonetheless, research continues apace, with researchers justifying their interest in mind wandering through two claims: (1) that any activity that occurs so frequently during states of consciousness--estimates range from $30 \%$ to $50 \%$ of the time--must be critical to the mind's and brain's operations in toto; (2) that mind wandering appears to play an important role in human flourishing and in relation to various kinds of psychopathology (e.g. Fox et al. 2015; Seli et al. 2015). Mind wandering is thus the site at which a number of unresolved ontological, normative and epistemological questions converge within psychological research.

Laboratory practices have repeatedly assumed that experimental subjects must have some task to wander from, and researchers have just as repeatedly defined mind wandering in opposition to external tasks (at times, in opposition to tasks per se). The coalescence of mind wandering as a scientific object owes much to the methodological and epistemological exigencies of task-based paradigms, which have unfolded a space in which mind wandering could take shape (Callard and Margulies 2011). The field is currently debating how mind wandering might be modeled, especially in relation to psychological descriptors of mental activity such as taskunrelated, stimulus-independent, spontaneous and internally-oriented thought. If some of the earlier research conflated these terms, there is now an increased parsing of these descriptors. And yet there remains a tendency to operate with dichotomous divisions: task-related versus taskunrelated; on task versus off task; externally oriented versus internally oriented; constrained versus spontaneous; goal-directed versus non-goal-directed. This helps to shore up a model in which mind wandering is understood as a spontaneous, internally-oriented, stimulus- 
independent process where attention is decoupled from perception (e.g. Smallwood and Schooler 2015). Additionally, the exigencies of psychological experimentation mean that, whatever the interest in developing methods to capture spontaneous dynamics of thought, the concept of the task remains one of the central elements that holds together the experimental psychological scene.

In our interdisciplinary experiment on mind wandering, the first author (Morrison) worked creatively to adapt the procedures and methods of a laboratory psychological experiment in order to generate rich qualitative data on participants' experiences of this phenomenon. As part of a larger project, the hope was that these data might be set against participants' neuroanatomical and neuropsychological measures, to create, inter alia, some richer taxonomy of mind wandering experience. In order to parse those data, the qualitative researchers on the grant (Morrison, Callard, Fitzgerald) brought together other social scientists and humanities researchers (McBriar, Powell, Proudfoot, Stanley) with varied expertise in historical, spatial, rhetorical and discursive analysis. In the next section, we describe that method in detail.

\section{An Interdisciplinary Experiment on Mind Wandering}

In STS and related literatures, scholars have devoted considerable attention to parsing constitutional differences between forms of inter-, trans- and cross-disciplinary research (see for example Thompson Klein 2010); others have taken seriously the question of how interdisciplinary projects are both produced and experienced (Bruce et al. 2004); while still others move to reflect in a more ethnographic mode about what it means to do STS research in unavoidably interdisciplinary contexts (Balmer, Bulpin and Molyneux-Hodgson 2016). The writing that some of us have done on this topic (Callard and Fitzgerald 2015; Fitzgerald and Callard 2015), has sidestepped this conversation in search of a wider problematization of the emergent field of interdisciplinarity. This wider problematic, which feeds into the analytical methodology of our own interdisciplinary mind wandering experiment, is the need for experimental design that promotes modes of "entangled" interdisciplinary research, in which sets of expertise, research questions, and outcomes are not split evenly by discipline, but are allowed to remain in suspension as the project advances (see also Powell, Morrison and Callard 2018).

This interdisciplinary experiment received ethical approval from the University of York Psychology Department on March 10, 2016. Nineteen participants (almost all undergraduate psychology students; almost all female) gave free and informed consent, and were asked to record nine detailed descriptions of episodes of mind wandering that they experienced over a three-day period. On the fourth day they (individually) attended a qualitative interview. The intention was to generate, through discussion of these episodes, a shared understanding between interviewer and interviewee of mind wandering, as experienced by the participant. In preparation for these interviews, the first author (Morrison) gave a thought experiment to participants, designed to shift their attention from recording what they mind wandered about to how they experienced the act of mind wandering. Drawing attention to pre-reflective dimensions of conscious experience (the how rather than the what) is believed to aid participants in reporting 
on specific and genuinely lived experience. To achieve this, Morrison deployed an "imagine an elephant" training task derived from Claire Petitmengin (2006). A definition of mind wandering from the psychologist Michael Corballis was also given to participants, which, while laying out common cultural conceptions of the term, went on to stress the ambiguous and evolving nature of its definition:

Mind wandering ... often occurs when we're "supposed to be concentrating on something [external]" ... yet we find our thoughts have drifted from the task at hand ... (Corballis 2015, citing Smallwood)

The hour-long, semi-structured interview, in which participants described and discussed their mind wandering episodes, was largely iterative: drawing on explicitation interviewing methods (Høffding and Martiny 2016), which foreground experience, and draw on phenomenological techniques and principles, participants were encouraged, through open-ended questioning, to produce subjective descriptions of their self-recorded experiences of mind wandering. Participants were then asked to be self-reflective; to assess if, and how, the task of recording and reporting on their mind wandering episodes had (a) informed, altered or matched their understanding of the phenomena, and (b) altered their experience of the phenomena under investigation. We asked such questions of the participant because a principal difficulty with psychological models of mind wandering is the reliance on the laboratory as a space for eliciting mind wandering experiences. Such experiences might not be analogous to what occurs outside: as one research group puts it, "general mind-wandering theories based largely or completely on laboratory findings do not capture all of mind-wandering's causes or correlates as it actually occurs in daily experience" (Kane et al. 2017).

The interviews produced 161 individually reported mind wandering episodes, which were recorded, transcribed verbatim, and analyzed. The first author undertook the initial process of analysis. Subjecting the transcripts to repeat readings, a large set of descriptive codes was drawn from the qualitative data using the data analysis software NVivo. In alignment with the methodology of Petitmengin (2006) these codes made participants' descriptions of how mind wandering phenomena were experienced in distinct, quotidian settings distinct from selfreflective, explanatory descriptions of what was experienced. The descriptive categories were then condensed and refined, before the transcripts were uniformly coded. To date, this is one of relatively few attempts made to investigate the form and content of mind wandering episodes where the coding structure is grounded in qualitative interviews conducted outside laboratory conditions (Antrobus, Singer, and Greenberg 1966; Stawarczyk 2018).

After coding was completed, the anonymized transcripts were shared with a larger experimental group that included all authors of this paper. Through subjecting the interview data to heterogeneous, more-than-social-science modes of reading and interpretation, we planned to shift the epistemological possibilities beyond the modes of either the psychological or the social sciences (Fitzgerald and Callard 2015: 18). Following an initial, invitation-only workshop, the transcripts were issued to, and individually analyzed by, all of the present authors. All authors 
then re-convened for a workshop, where they discussed their analyses, came to a shared account of the central issues at stake in the data, and began the present paper. It was there, as the coding of the transcripts moved from descriptive categories to a series of analytic categories, that task emerged as the central problem for conjoint analysis: task was an object that was not only centrally (if obliquely) present in the set-up of the experimental procedure; it also appeared in participants' accounts of how they interpreted and worked through that procedure. This iterative cycle of coding and analysis is methodologically aligned to the application of grounded theory (Giles 2008). Rather than use data to test pre-defined hypotheses, task emerged as an analytic category from the bottom up, such that theoretical understandings emerged from the research data. In the following sections, we present fragments from our interview material that demonstrate with particular clarity the core conceptual issues with which we are engaged in relation to task. All names are pseudonyms.

\section{The Porosity of Task}

For many people, thinking about mind wandering generally means thinking of oneself in relation to some external task:

\begin{tabular}{|c|c|}
\hline Margaret: & $\begin{array}{l}\text {... my, from this like um, making notes of my ... how my thought } \\
\text { wanders ... }\end{array}$ \\
\hline Interviewer: & $\mathrm{Mm}, \mathrm{mm}$. \\
\hline Margaret: & $\begin{array}{l}\text {... it kind of became clear that when I think of, or when I'm engaging } \\
\text { particular, um tasks ... that soon after my mind kind of wanders and } \\
\text { like I'll dream of what can actually come out of whatever it is ... Um, I } \\
\text { think that's just how my mind works I think. }\end{array}$ \\
\hline
\end{tabular}

For Margaret, to catch herself mind wandering is to catch herself going off task. But how do participants, in an experiment like this one, understand such a process to work? Consider a specific instance of mind wandering experienced by Alison, whose mind wandering episode involved the fast-flowing development of numerical patterns:

Okay this one ... eh, yeah ... I was in a lecture and I got distracted. I ring church bells, and we learn different methods for like different patterns of the bell ... and I got really distracted ... trying to work out a method, they're called plain hunt, ... this involved ... numbers and so I was thinking about it in thoughts but also I could see it, see the numbers. I could see them changing and that's where you get the pattern from ... I zoned out of the lecture completely ...

Scientific paradigms investigating mind wandering commonly give participants tasks that "systematically vary ... levels of attentional demand," with undemanding tasks seen to maximize the potential for mind wandering to occur (Antrobus 1968). This has worked well within the laboratory, enabling a dichotomy to be drawn between extrinsic and intrinsic sources 
of cognition, and between task-related and task-unrelated thought. In 2006, Smallwood and Schooler, in an article that was central in propelling mind wandering research out of the margins, elaborated on mind wandering as deviation from a primary task. Yet they also proposed that mind wandering could be seen as a goal-oriented process--in which executive control shifts away from a primary task to the processing of personal goals" (2006: 946). While this model extended the utility of task-centric definitions, it raised difficulties, given that a primary task is not always clearly situated when body, mind and brain are embedded in a socially complex environment. This seems to be the case with Alison, whose attention was focused not on the lecturer, but on notation for a musical piece she was working on. Having worked through this problem, Alison reported feeling "pleased with the distraction because [she'd] successfully worked out the method ... and then returned to the lecture," so while demonstrating a shift of attention away from the lecture (external task), the contents of her mind wandering episode were far from task free.

In other cases, the distinction between being on and off task was blurred, as detached, reflective thinking co-occurred with participants' engagement with the environment. As Gordon pointed out: "I am a good model student, even if I'm daydreaming I try to keep the lecturer's speech in some level of awareness." Or consider Kate, who recounted that while trying to figure out why an instrument that looks like an oboe can have the sound of a trumpet, her mind wandered to thoughts of a future scenario that held personal salience: "I thought of coming back in winter with a second-study instrument rather than just having singing." Kate understood herself to have mind wandered from within a mental task, in which her attention was already internally focused; the shift was not from external to internal, as is commonly assumed in scientific literatures, but between one internal state and another.

Maedhbh described jogging when her mind wandered to thoughts of an upcoming visit from her family. It was here that she began to fantasize about shopping for bikinis in preparation for their holiday. This train of thought was broken when she arrived at the thought that in order to "look nice" she would have to be physically fit, and this prompted her to increase her jogging pace:

... because we're going on holiday. But then imagining that sort of made me think of right, if you want to look nice in a bikini you're going to have keep running faster ... and then I sort of started running a bit faster.

Maedhbh's mind wandered from her primary activity of jogging to thoughts typical of mind wandering--those relating to "the future, the self, other people" (Smallwood and Schooler 2015: 489). Interestingly, the thoughts about her self-image did not simply return her attention to the primary activity but did so in such a way that they bid her to perform the activity differently. Ideas generated during the episode produced new ideas about the primary activity--pointing to the importance of attending to the dynamics that fold together mental and bodily states variously oriented to material and imagined worlds. 
In this section, the operational pliability of task is demonstrated in the difficulty of distinguishing between (primary) task and mind wandering, even in cases of seemingly archetypical off-task activity. In particular, the slippage of task from the laboratory to spaces beyond evidences both the porosity and the overdetermined nature of quotidian tasks. By porous, we mean that task beyond the laboratory can often only be categorized as discrete activity by a kind of sleight of hand: quotidian tasks in fact exceed their categorization and resist separation from other, supposedly distinct tasks. Similarly, tasks are overdetermined: they are complex mental and social phenomena that engage subjects cognitively and emotionally. This makes it difficult, again, to isolate task from non-task. Only in relation to artificially simplified tasks do definitions of mind wandering come into existence. Our participants' formulations pose the intriguing question of whether, outside of the laboratory, mind wandering might simply be experienced as one of many modes of thinking through which people approach and apprehend their world.

\section{The Dynamics of Going Off Task}

I think the problem with their [laboratory-based, psychological] experiments is your mind ... A lot of the mind wandering is because you're bored rather than because it's spontaneous thought because it's a concern. You have to press the left or right button, so it's not necessarily that you're wand ... Well, yes, you can be easily be bored, too, doing revision but it's not necessarily just completely spontaneous. You're kind of wanting to think about something else to pass the time, really [Ella].

Many participants, while not insensible to the slippage between the contrived tasks meted out in the experimental situation and everyday activities, did nonetheless latch on to task as the central element against which mind wandering was adjudicated. As May-Lee stated, "It's basically ... when you're sort of thinking of something that's deviating from the task that you've got in front of you." This is not unexpected: the instructions explicitly defined mind wandering in contradistinction to task. Furthermore, for participants versed in psychological procedures, task would have been an obvious yardstick by which to measure mind wandering. But even as our participants were beholden to the constraints of psychological experimentation, an analysis of the transcripts puts further pressure on these distinctions. In this section, we move between our participants' accounts and some of the models mobilized in scientific investigations of mind wandering, to offer a more textured account of the operational pliability of task. We show that standard models of task, with their connotations of boundedness, direction and imposition, do not do justice to the dynamics through which participants' worlds are constituted.

For many participants, the identification of a location or activity was the starting point for their mind wandering narratives. Statements such as "I was in a lecture," "revising for an exam," or "looking on Facebook" were commonly used when indicating the primary activity from which their thoughts were to wander. For a number of participants, the elision between activity and task was presented in an unproblematic fashion. And yet, when pressed, many 
refined the nature of their primary activity. Asha, a reader of fantasy novels, demonstrated confusion over the relationship of task to mind wandering, as the transformative effect of mind wandering upon her experience of the primary task of reading was registered as both on and off task:

I was trying to read Game of Thrones and at the beginning I was ... Yes, I was enjoying it, reading, but I couldn't concentrate because I just kept picturing the scenes off the actual TV show.

This, she related,

made it hard to, um, concentrate and focus actually on the words and the reading of the book. Um, I guess it was ... It was daydreaming, but it was about the topic but it still made it hard to focus on what I was trying to do.

Here Asha expressed a nuanced formulation of mind wandering: while the contents of her wanderings were related thematically to what might be considered a task, they were unrelated to the goal of focusing on the text (see Poerio 2016). Within the context of her interview, this overlap produced some confusion, demonstrating tensions between the experiences Asha recounted, and her explicitly stated and task-centric definitions of mind wandering.

As participants began to unpack the constituent parts of their mind wandering episodes, they sometimes gave details of multiple inner spatialities and temporalities inhabited in their mind wandering. Illaria related an episode in which she "kept, like, seeing myself, like, on the beach or on the mountain, but I don't know if that's because I've seen pictures of me up a mountain, on beach recently ... It's sort of like old images but in different places." And then later: "I just made up places. I'm not really sure where they are." This spatial and temporal collapse appeared in Carl's account of an episode in which he experienced images of his handwriting within the space of the exam room while making breakfast: “... we were in the exam hall and I can sort of picture that there were railings that were there, but as I say it was kind of distant from any experience that I've had before, it wasn't like I was sat in the same seat that I had been in before," and then, "... I remember being in the same sort of room but not there at that place. It's not a memory, no." Accounts like these suggest a nuanced overlap of the real and imagined that bordered on simulation. Such superimpositions are rarely accommodated in psychological experimentation-where the dyadic field in which one is either on or off task is commonly accompanied by dichotomous characterizations of off-task experiences such as past or present, real or imagined.

When participants described the spatio-temporal movements of their mind wandering being curtailed, they often referred to forceful, and affectively charged, self-talk. Such self-talk was often described in relation to task, as self-talk came to buttress a return to the demands of task. Consider Kate: 
And then when I realized I'd been doing this for like two times, song through, I was like I've got to snap out of it ... I'm like, this is not the time to be thinking about this. I should just clear my head and think about what's happening right now.

Kate reported being critical of herself for not having paid attention to the activity she deemed to be morally and/or socially demanded of her. This feeling of obligation involved psychological "inner speech"--Kate was giving herself a talking-to. In recent years, inner speech has been recognized within psychology as exercising an important role in the self-regulation of cognition and behavior, particularly in the fields of multitasking and motivation (Alderson-Day and Fernyhough 2015). In these interviews, instances of inner speech were often credited with having brought the participant out of her reverie and were directed towards a goal that was personally relevant and/or affectively loaded. Asha pictured herself as a lecturer, and then said to herself: "the only way you're going to be able to do something like that is if you concentrate on the lecture. [...] so I think that kind of brought me round." Eilidh, having "wandered" to thoughts of her boyfriend after being aggravated that he hadn't texted her back, "just chose to kind of be like: okay, don't need to think about it right now."

Participants also employed inner speech to articulate anxious feelings about deviating from activities clearly construed as tasks: Jo said: "And then, I was like, actually, I need to get back to work." But it also featured in decisions and resolutions in the form of self-commands: Ella recalled telling herself: "Right, do some work, then go home and stop getting distracted." Occasionally the self-talk could be categorized as abusive but good-humored. Meagan was brushing her teeth during a mind wandering episode and mistook the laundry bin for the basin: "And I sort of looked at myself and like you're a complete mug [...] and like, what are you doing?" Several participants, faced with the need to account for the time away from their task resorted to self-talk to puzzle this out: Carl said, "I was just thinking to myself "Why am I thinking about cheese?'" These linguistic utterances take those who utter them to task--and, in so doing, bring them back to task. The distinction between internal and external focus is thus thrown into some confusion.

The interviewees were rarely straightforwardly positive about their mind wandering experiences, but when they were it was usually associated with a reordering of goals, which pointed to the need to understand their subjective account of what constituted the important task at hand. Alison "zoned out of the lecture," we should recall, while thinking about that particularly tricky bit of bell-ringing, commenting: "I felt pleased with the distraction because I'd successfully worked out the method." Kate was watching a rehearsal and reported having been aware at the time that her thoughts were drifting, specifying: "I'm happy that the thoughts are progressing ... I was definitely letting them progress. Even though I shouldn't have done, I was definitely then going over the things that I need to do." Working out a new ringing pattern and compiling a To-Do list were higher priorities for Kate than listening to the lecture or watching the rehearsal. In both cases, mind wandering was endorsed because it had been of some cognitive and moral benefit to the individuals. In such instances, the mental tracing of task-completion and 
of mind wandering were so entangled that they threatened to collapse any explanatory matrix in which it might be assumed that task and wandering could be held separable from each other.

In this section, we have explored the extent to which task, or some more nuanced notion of it, is able to demarcate elements of our participants' spatially, temporally, affectively and morally complex psychosocial worlds, in ways that are not yet well accounted for in the scientific literature. Again, construals of task in participants' accounts differ markedly from the straightforward dichotomy that the psychological research community has commonly relied upon. Our participants' elaborations of the dynamics of spatial and temporal movement--in both their inner and outer worlds-offer other kinds of topologies through which both task and wandering might be traced. In the final empirical section, we consider this possibility in greater detail through the analytic lens of metaphor. Here, the operational pliability of task manifests through its ability to vary between that which needs to be accomplished via the commandeering of space and time, and that which marks, in a much more open form, that which is to be done.

\section{The Mutability of Metaphor}

It is no surprise that, in interviews with mind wandering research participants, their talk is riven with the form and logic of task; that they are given to understand and account for themselves through the bifurcated logics of focus and inattention, of wandering and staying put. But you also find-and this has been the central thrust of our article-that when you push at these accounts, participants unspool more nuanced, contingent, and varied explanations of what it means for a mind to wander. We will show in this section that the metaphorical structure of the term "mind wandering" helps us to understand the back-and-forth between participants' understandings of task, its wider role in experiments in mind wandering, and its complex historical presence in psychological experiments. We pointed earlier to the historical legacy of task, as that which binds the participant to the experimenter--a relationship that is intended to orient the exchanges between each of them, but that also shapes the participant's awareness of the task she needs to perform. We now consider the central role of task in the creation and sustenance of the metaphorical structure of mind wandering. As we have noted already, the explicit discourse and definitional rubrics of both psychology and our participants privilege a task-centered, goal-oriented definition of wandering as a deviation from a fixed course. How might the scientific culture of the psychological experiment be prized open through a more openended sense of wandering as free movement? Would a metaphor that emphasizes the ability "to roam, ramble, go idly or restlessly about" (Oxford English Dictionary, 1921) open up some of the central questions at the heart of our article?

As the definition suggests, the term wandering reflects a strong, culturally embedded sense of the movement between, and indeed conflation of, external and internal spaces. From Wordsworth to Woolf (Wordsworth, 1984 [1805]: 582-583 [The Prelude, Book XIII, lines 166-181]; Woolf 2008 [1921]), landscapes of consciousness are often imagined in terms of physical terrain and vice versa, and the boundaries between them as transient and ambiguous. Thus the role of wandering in the cultural imagination contrasts sharply with scientific definitions of mind 
wandering which are based on the presumption of a linear, task-directed path, while at the same time allowing a means by which to explore the spatiotemporal complexity of the internallyfocused task. Below, Illaria departs from an external task only to resume external focus, afforded by a vision of herself within the episode:

I get really distracted easily, and then I think about what if ... I, like, failed exams in uni ... I ended up thinking about me working in Sainsbury's ... On like the checkout and being looking really like chavvy ... And then apparently I was also a young mum and then I had a pink sort of tracksuit on; that was weird ... Like, that's what life could have been? ... But then it was sort of like ... the future, but it was the past and I said it's sort of like, oh, this is what it could be like but then, for some reason, I was younger in it ... But I was still thinking about the future ...

Here, rather than Ilaria's wandering representing the movement away from task--away from a pre-established path--her wanderings bind an appreciation of self with motivations and consequential understandings of the task of revision: neither internally- nor externally-focused thought processes can be considered as mutually independent. This is an alternative to the linear, sequential and narrative sense invested in a determined movement away from the task and back again, or the way in which "self-generated mental activity interrupts" the pre-established path (Callard et al. 2013: 9).

So why is the metaphor of mind wandering, when it appears in mainstream psychological writing, so wedded to notions of linearity? Much of this can be traced to a constrained reading of William James's "stream of consciousness," a metaphor against which mind wandering is commonly situated, and to which it is indeed "essential" (Smallwood and Schooler 2015: 487). While seemingly contradictory, these images can be made to work together with some dexterity, where the task itself takes on the quality of the unidirectional stream from which the mind wandering episode deviates (like the rock or eddy, which causes the water to circulate back in upon itself). However, James's metaphor is not as constrained as it might appear. Jerome Singer, an early scientific investigator of daydreaming and mind wandering, has argued that James "decided upon the word 'stream' because he wished to emphasize the elements of seeming continuity of thought, recalling Heraclitus's famous image that one never steps twice in the same place in a flowing stream" (Singer 1975: 728). Singer's account relies on a translation of the river fragment found in Plato; but this original fragment is possessed of a great deal more spatio-temporal complexity: "On those stepping into rivers staying the same other and other waters flow" (Graham 2008: 173). Rather than underpin James's direct comparison between the continuity of consciousness and the stream, this fragment is more suggestive. The complexity hinges on this sense of a river that conceivably "stays the same," but in which "other and other waters" flow (Graham 173). The dynamic nature of this opposition carries with it that same openendedness of wandering, figured now as a more spatially open and temporally complex movement. It also suggests a more substantive relationship between internal and external states, as it is not about where one steps, or the fact of not stepping twice "in the same place," but rather about the continually changing nature of the water that makes contact. 
One participant, Alison, recalled seeing a goose in the park outside her room. Later, as her mind wandered from reading, she looked out the window:

the goose had gone but, and it's weird because I noticed the thing yesterday ... a couple of days ago, there was something ... it must be from, it must have been some wrapper or something that's been left on the path so that it catches the sun, and it's gold, and it had been there a couple of days ago but the goose was sitting on it. So the goose left. It made me think, I was probably very tired ... it made me think, you know, Jack and the Beanstalk. The goose that lays golden eggs.

Here, the mental and the environmental weave together in a manner that points to their permeability rather than their sequestration. The physical and mental movements of goose and gold comprise a looping path that is not best described as a determined movement towards and away from a narrowly prescribed task (or, indeed, as a simple shift from external to internal, or from goal-oriented to spontaneous).

Current scientific research is challenging the previous dominant, linear model of mind wandering as deviation from an externally-driven task. Christoff and colleagues, for example, emphasize the dynamic complexity of task-a complexity that is able to include attending to "one's personal concerns," thus shifting the primary seat of task from the external environment to inhabiting internal states (Christoff et al. 2016). This repositioning of task has encouraged a more mobile view of the movement between external and internal states. People's narratives of mind wandering, as this research is beginning to indicate, often lack in coherence; are permeated by, or overlap with, a highly skilled and nuanced sensitivity to small shifts within the external environment; and at times seem to evolve in play with elements of both physical and cognitive environments. Christoff and colleagues have also attempted to shift the metaphors that have been borrowed from James: whether it is the "alternation of flights and perching" or the punctuated segments of a sentence, it is commonly the sense of continuity in James that is foregrounded. But these metaphors invite further exploration for what they can afford beyond the "on/off task" model. Christoff and colleagues, in this respect, have shifted from a focus on the "perch" to the dynamic nature of flight itself-as we can imagine the bird's movement as more directionless, like the wanderer, flying through unknown terrain, alighting or not alighting on unfamiliar branches.

Our argument here opens up the spatiotemporal complexity of both task and mind wandering as an essential feature of their operational pliability. While there is much more that might be said, we have brought a longstanding STS interest in the role of metaphor in the sciences (Keller 1999) into relation with ways in which metaphor works in psychological experiments on mind wandering. Metaphor both shapes and is shaped by scientific methodology; and entrenched metaphorical readings of texts carry certain assumptions. As our data show, it is not that the metaphorical deployment of task, and cognate terms, in assessments of mind wandering experience is somehow misplaced. Rather, the porosity of mind wandering experiences is ill-served by the constrained metaphorical deployment of task in the psychological 
literature. This metaphorical deployment forecloses the ability of psychological research to encounter the more multiple notions of task that appear in our interviews.

\section{Conclusion}

In this article we have provided what we believe to be the first sustained analysis of an everyday and key element of the psychological experiment, the task. Drawing on qualitative interviews with mind wandering research participants, we have shown that task is deployed and understood in multiple ways: it is often hard to distinguish when a person is on task and when they are not; when participants reflect on their own internal states the boundedness that the concept relies upon is drawn sharply into question; and the complex spatio-temporal organization of experiences of mind wandering and of task disrupts the metaphorical structures that the scientific literature has baked into these terms. An experiment concerning mind wandering, specifically, was a privileged site through which to examine these terms, given how centrally mind wandering has been conceptualized in relation (or contradistinction) to task. Nonetheless, we argue that such multiplicity is likely to accompany the wider operationalization of task as it is deployed in psychology.

The term operational pliability has been central to our analysis of this situation. We used this term to show that at the heart of our findings is a certain kind of pliability of the practice and concept of task. Within the broader setting of the experiment, task is the form of instruction, and that which the participant is instructed to attend to; it describes the phenomenon of investigation and the wider apparatus in which that investigation takes place. The operational pliability of task powerfully structures the "experimenter-subject system" (Morawski 2015: 574)—not only because it shapes the customary interactions between experimenter and experimental subject, but also because it determines how such interactions, and the mental states they are assumed to highlight, are modeled and understood. An experimental subject in a mind wandering experiment, by taking on that role, is interpellated in relation to task in three ways: (i) her task is to become an experimental subject (with all the psychosocial demands that such a role implies); (ii) her task is to respond to the task set by the experimenter (with all that might diverge in the movement between the task set and the task as actualized); (iii) her task is to account for her experiences of being off task. Through attending to the operational pliability of task, we have shown that the demands of (i) are commonly disavowed; that there is substantial heterogeneity in how (ii) is undertaken and experienced; and that efforts to accomplish (iii) challenge understandings of task as a linear and constrained activity that originates in the external world. Task is, in fact, that from which one wanders; sometimes, that to which the wandering takes place; and sometimes that which comprises wandering itself. Task means both remaining inside a particular mental space, and leaving it too. And wandering from a specific task has a much more unpredictable trajectory than that assumed by a determined movement that interrupts a clearly delineated linear path. The operational pliability of task is central to how mind wandering experiments operate. We do not argue that either the research participants or the psychologists are mistaken in their grasp of task. Rather, we argue that at the heart of these experiments is the capacity of this element, the 
task, to operate as both a straightening and an expanding device: task simultaneously keeps the elements it binds in order, and proliferates the ways in which those elements dynamically articulate with one another. And it seems to us, finally, that this may not be a unique situationthat there are other elements, in various kinds of scientific investigation, that carry such operational pliability.

In this regard, our paper makes three core contributions to STS. First, we propose greater attention to the undertheorized contributions of mundane, low-tech aspects of scientific experimentation-particularly, but not solely, within the psychological sciences. An element like "task" does not carry the sophistication of a scientific model or the complexity of a semioticmaterial infrastructure, but is no less potent in its ability to bring the material and immaterial, the technical and the subjective, into alignment. Second, we emphasize that operational pliability offers a way of understanding how particular elements in scientific investigation are easily adaptable, and at the same time are able to hold some kind of shape or form. When we first alighted on task as a central focus for our analysis, we were struck by the multiple ways in which it worked and was put to work. Task was both the form and substance of instruction; it was the ground of the experimental apparatus and the psychological phenomenon that the apparatus sought to grasp; it made up the structure of how participants accounted for their moments of deviation, and was the very stuff of deviation itself. But we have also shown how this operational pliability was itself predicated on specific forms of constraint-that, perhaps counter-intuitively, it is the intensely straitening effects of the metaphorical, disciplinary and other legacies through which task operates that enables its multiplicity. ${ }^{3}$ To put it otherwise: it is precisely in edging participants away from more affectively, temporally, spatially and introspectively charged relationships to task and deviation that the tasks and task-relationships of mind wandering research are able to do such varied work. Multiplicity, as Michelle Murphy reminds us in another context, is no simple "eschewing of reductionism": multiplicity, rather, precisely in allowing some things, specifically disallows some others (Murphy 2006: 150). So too does the pliability of our experimental element not mean bending in all directions. Perhaps, indeed, the opposite. Third, pliability is a characteristic of (biddable or docile) people as well as (ductile) substances. Mutability, stability and intimacy in experimental situations are, we want to stress, dependent on the configuration of human as well as non-human entities. While STS has been wary of the figure of the human subject, our use of the term operational pliability is intended to emphasize how scientific relationships and interactions bring certain kinds of psychological and sociotechnical forms into visibility.

On a final note: psychological experiments take place in a society where the concept of task lubricates social relations as well as the organization of space and time. (On-task and off-task behaviors now structure the educational scene (Wood et al. 2012); customers can use TaskRabbit to book Taskers to get their own tasks done.) It is not by chance that the anxious literature on mind wandering, including that with which we began, has been concentrated in business and management journals. The language of task is so resolutely embedded in the psychology and

${ }^{3}$ We have used two different words and spellings (straightening and straitening) in this concluding section, as one marker of the multiplicity with which we are preoccupied analytically. 
cognitive neuroscience of mind wandering that it is difficult to imagine it being dispensed with. But such a language, while pliable and capacious, is put under pressure by the mental and bodily phenomenon-mind wandering--with which we have been concerned. Generating and working with more digressive models of both task and of mind wandering-even as task continues to act as one of the central generators for psychological laboratory experimentation and for the organization of everyday life-might expand how we understand the nature of psychological investigations inside and well beyond the laboratory. It might also help us to think more imaginatively about what is at stake-culturally, politically and scientifically-in the wandering mind.

\section{Author Biography}

Hazel Morrison is an interdisciplinary scholar, whose work contributes to the growing field of the critical medical humanities. Her research interests range from studies of psychopathy, patient case notes and the paradigmatic patient, to the wandering mind in relation to phenomenology, experimentalism and "being human." She conducted the research for this article while a postdoctoral research associate in the Department of Geography and the Centre for Medical Humanities at Durham University. She is currently a research assistant at the University of Edinburgh.

\section{Author Biography}

Hilary Powell is an honorary research fellow in the Department of English Studies at Durham University. A medievalist by training, she has worked on several Wellcome-funded interdisciplinary projects in the medical humanities. Her recent publications examine cognitive and literary approaches to countering daydreaming in the medieval monastery.

\section{Author Biography}

Shannon McBriar is Lecturer in Humanities at Amsterdam University College, The Netherlands. Her research focuses on the theory of affordances in relation to mind wandering and uncertainty, and she is a frequent contributor to interdisciplinary research seeking to encourage dialogue between cognitive science, theory, and fiction.

\section{Author Biography}

Jesse Proudfoot is an Assistant Professor (Research) and Marie Curie Junior Research Fellow in the Department of Geography and Institute for Medical Humanities at Durham University. His research examines drug addiction and addictions treatment through ethnographic fieldwork with drug users. His published work has examined problems at the intersection of geography and the 
medical humanities, including the relationship between place, trauma, and addiction, and the libidinal economies of drug policy.

\section{Author Biography}

Steven Stanley is a critical psychologist in the School of Social Sciences at Cardiff University. He is interested in therapeutic cultures and the history of psychology, especially in relation to Buddhism. He co-edited Handbook of Ethical Foundations of Mindfulness and is currently leading the Mapping Mindfulness project, a social study of the UK mindfulness meditation movement funded by The Leverhulme Trust.

\section{Author Biography}

Des Fitzgerald is Senior Lecturer in Sociology at the School of Social Science, Cardiff University. $\mathrm{He}$ is the author of Tracing Autism: Uncertainty, Ambiguity and the Affective Labor of Neuroscience (University of Washington Press, 2017) and, with Felicity Callard, Rethinking Interdisciplinarity Across the Social Sciences and Neurosciences (Palgrave, 2015).

\section{Author Biography}

Felicity Callard is Professor of Social Research and Director of the Institute for Social Research at Birkbeck, University of London. She is the author, with Des Fitzgerald, of Rethinking Interdisciplinarity Across the Social Sciences and Neurosciences (Palgrave, 2015), and Editor-in-Chief of History of the Human Sciences. She is researching mind wandering, daydreaming and fantasy in the twentieth- and twenty-first century human sciences.

\section{Note on Contributions}

Hazel Morrison designed and conducted the interview study, in consultation with Felicity Callard and Des Fitzgerald. All authors were involved in the analysis of the interview transcripts, and in the research for and writing of the article.

\section{Acknowledgements}

This research was funded by The Volkswagen Foundation [through grants AZ 89436 and AZ 90 169 awarded to Felicity Callard and Des Fitzgerald for the interdisciplinary project "Wandering Minds: Interdisciplinary Experiments on Self-Generated Thought" (undertaken with two other investigators: Daniel Margulies and Jonathan Smallwood)] and The Wellcome Trust (through the grant to Hubbub [103817/Z/14/Z]). We thank Giulia Poerio, who guided us through the ethics process for psychological laboratory experimentation, who aided in participant recruitment, and 
whose expertise in the history and phenomenology of mind wandering research in psychology shaped the wider experimental protocol. Also Jonathan Smallwood for hosting the experiment and providing further guidance. We thank all the participants who participated in the interviews. The contributions of invited delegates to the workshop "Wandering Minds: Interdisciplinary Experiments on Self-Generated Thought," held at The Wellcome Trust in January 2016, were very helpful in shaping the empirical study; in addition to the authors of this paper, the delegates were: Ben Alderson-Day, Micah Allen, Kelly Benneworth-Gray, Marco Bernini, Danilo Bzdok, Marshall Dalton, Sarah Garfinkel, Peter Garratt, Chris Jack, Beth Jeffries, Daniel Margulies, Charlotte Murphy, Holly Pester, Steve Pile, Giulia Poerio, Jérôme Sackur, Jonathan Smallwood, and James Wilkes. Responsibility for the contents of the article lies with the authors alone.

\section{Disclosure Statement}

No potential conflict of interest was reported by the authors. The authors declare that the research was conducted in absence of any commercial or financial relationships that could be construed as a potential conflict of interest.

\section{References}

Alderson-Day, Ben, and Charles Fernyhough. 2015. "Inner Speech: Development, Cognitive Functions, Phenomenology, and Neurobiology." Psychological Bulletin 141(5): 931-965.

Ali, Sabrina S., Michael Lifshitz, and Ali Raz. 2014. "Empirical Neuroenchantment: From Reading Minds to Thinking Critically." Frontiers in Human Neuroscience 8.

Antrobus, John S. 1968. "Information Theory and Stimulus-Independent Thought." British Journal of Psychology 59(4): 423-430.

Antrobus, John S., Jerome L. Singer, and Sean Greenberg. 1966. "Studies in the Stream of Consciousness: Experimental Enhancement and Suppression of Spontaneous Cognitive Processes." Perceptual and Motor Skills 23(2): 399-417.

Ashmore, Malcolm, Steven D. Brown, and Katie Macmillan. 2005. "Lost in the Mall with Mesmer and Wundt: Demarcations and Demonstrations in the Psychologies." Science, Technology \& Human Values 30(1): 76-110.

Balmer, Andy S., Kate Bulpin, and Susan Molyneux-Hodgson. 2016. Synthetic Biology: A Sociology of Changing Practices. Basingstoke, Hampshire: Palgrave Macmillan.

Baum, Carlos. 2016. "Stabilizing Cognition: An STS Approach to the Sloan Foundation Report." Theory \& Psychology 26(6): 773-787.

Bruce, Anne, Catherine Lyall, Joyce Tait, and Robin Williams. 2004. "Interdisciplinary Integration in Europe: The Case of the Fifth Framework Programme. Futures. (Transdisciplinarity) 36(4): 457-470.

Callard, Felicity, and Daniel S. Margulies. 2011. "The Subject at Rest: Novel Conceptualizations of Self and Brain from Cognitive Neuroscience's Study of the 'Resting State'." Subjectivity 4(3): 227-257. 
Callard, Felicity, Jonathan Smallwood, Johannes Golchert, and Daniel S. Margulies. 2013. "The Era of the Wandering Mind? Twenty-first Century Research on Self-Generated Mental Activity." Frontiers in Psychology 4:891.

Callard, Felicity, and Des Fitzgerald. 2015. Rethinking Interdisciplinarity Across the Social Sciences and Neurosciences. Basingstoke: Palgrave Macmillan.

Christoff, Kalina, Zachary C. Irving, Kieran C. R. Fox, R. Nathan Spreng, and Jessica R. AndrewsHanna. 2016. "Mind-wandering as Spontaneous Thought: A Dynamic Framework." Nature Reviews Neuroscience 17(11): 718-731.

Corballis, Michael C. 2015. The Wandering Mind: What the Brain Does When You're Not Looking. Chicago, IL: Chicago University Press.

Danziger, Kurt. 1994. Constructing the Subject: Historical Origins of Psychological Research. Cambridge and New York: Cambridge University Press.

Daston, Lorraine. 2000. "The Coming into Being of Scientific Objects." In Biographies of Scientific Objects, edited by Lorraine Daston, 1-41. Chicago IL: Chicago University Press.

Derksen, Maarten, Signe Vikkelsø, and Anne Beaulieu. 2012. "Social Technologies: Crossdisciplinary Reflections on Technologies in and from the Social Sciences." Theory $\mathcal{E}$ Psychology 22(2): 139-147.

Fitzgerald, Des, Melissa M. Littlefield, Kasper J. Knudsen, James Tonks, and Martin J. Dietz. 2014. Ambivalence, Equivocation and the Politics of Experimental Knowledge: A Transdisciplinary Neuroscience Encounter. Social Studies of Science 44(5): 701-721.

Fitzgerald, Des, and Felicity Callard. 2015. "Social Science and Neuroscience Beyond Interdisciplinarity: Experimental Entanglements." Theory, Culture \& Society 32(1): 3-32.

Friese, Carrie, and Adele E. Clarke. 2012. "Transposing Bodies of Knowledge in Technique: Animal Models at Work in Reproductive Sciences." Social Studies of Science 42(1): 31-52.

Fox, Kieran C. R., Nathan Spreng, Melissa Ellamil, Jessica R. Andrews-Hanna, and Kalina Christoff. 2015. "The Wandering Brain: Meta-analysis of Functional Neuroimaging Studies of Mind-wandering and Related Spontaneous Thought Processes." NeuroImage 111: 611-621.

Giles, David C. 2008. Advanced Research Methods in Psychology. 1" edition. London and New York: Routledge, Taylor and Francis Group.

Graham, Daniel W. 2008. "Heraclitus: Flux, Order, and Knowledge." In The Oxford Handbook of Presocratic Philosophy, edited by Patricia Curd, and Daniel W. Graham, 169-188. Oxford: Oxford University Press.

Hayward, Rhodri. 2017. "Busman's Stomach and the Embodiment of Modernity." Contemporary British History 31(1): 1-23.

Høffding, Simon, and Kristian Martiny. 2016. "Framing a Phenomenological Interview: What, Why and How." Phenomenology and the Cognitive Sciences 15(4): 539-564.

Jack, Anthony and Andreas Roepstorff. Eds. 2003. Trusting the Subject? The Use of Introspective Evidence in Cognitive Science. Volume 1. Exeter: Imprint Academic.

Jersild, Arthur T. 1927. "Mental Set and Shift." Archives of Psychology, no. 89, ed. R. S. Woodworth. New York. 
Kane, Michael J., Georgina M. Gross, Charlotte A. Chun, Bridget A. Smeekens, Matt E. Meier, Paul J. Silvia, Thomas R. Kwapil. 2017. "For Whom the Mind Wanders, and When, Varies Across Laboratory and Daily-life Settings." Psychological Science 28(9): 1271-1289.

Keating, Peter, and Alberto Cambrosio. 2000. "Biomedical Platforms." Configurations 8(3): 337387.

Keller, Evelyn Fox. 1999. Refiguring Life: Metaphors of Twentieth-century Biology. New York: Columbia University Press.

Latour, Bruno. 1987. Science in Action: How to Follow Scientists and Engineers Through Society. Cambridge, Massachusetts: Harvard University Press.

Leonelli, Sabina, Rachel A. Ankeny, Nicole C. Nelson, Edmund Ramsden. 2014. “Making Organisms Model Human Behavior: Situated Models in North-American Alcohol Research, 1950-onwards." Science in Context 27(3): 485-509.

MacKinnon, Matthew. 2016. "The Dangers of a Wandering Mind." Available at: https: / / www.psychologytoday.com/blog/the-neuroscience-mindfulness / 201604 / thedangers-wandering-mind (Accessed: 28 July 2017).

Mandler, George. 2011. History of Modern Experimental Psychology: From James and Wundt to Cognitive Science. Cambridge, MA: MIT Press.

Morawski, Jill. 2015. “Epistemological Dizziness in the Psychology Laboratory: Lively Subjects, Anxious Experimenters, and Experimental Relations, 1950-1970." Isis 106(3): 567-597.

Morcom, Alexa M., and Paul C. Fletcher. 2007. “Does the Brain Have a Baseline? Why We Should Be Resisting a Rest." NeuroImage 37(4): 1073-1082.

Münsterberg, Hugo. 1913. Psychology and Industrial Efficiency. Boston: Houghton Mifflin.

Murphy, Michelle. 2006. Sick Building Syndrome and the Problem of Uncertainty: Environmental Politics, Technoscience, and Women Workers. Durham, NC: Duke University Press.

Nelson, Nicole C. 2013. "Modeling Mouse, Human, and Discipline: Epistemic Scaffolds in Animal Behavior Genetics." Social Studies of Science 43(1): 3-29.

Oxford English Dictionary (1921) "wander, v. 1a" Available at: http: / / www.oed.com/view / Entry / 225437?rskey=iiKEec\&result=2\&isAdvanced=false.

Oxford English Dictionary (no date) "Aufgabe, n." Available at: http:/ / www.oed.com/view / Entry / 13056?redirectedFrom=aufgabe\&.

Petitmengin, Claire. 2006. "Describing One's Subjective Experience in the Second Person: An Interview Method for the Science of Consciousness." Phenomenology and the Cognitive Sciences 5(3-4): 229-269.

Pickersgill, Martyn. 2011. “Ordering Disorder: Knowledge Production and Uncertainty in Neuroscience Research." Science as Culture 20(1): 71-87.

Pillay, Srini. 2017. "Your Brain Can Only Take So Much Focus." Harvard Business Review, 12 May. Available at: https://hbr.org/2017/05/your-brain-can-only-take-so-much-focus (Accessed: 28 July 2017).

Poerio, Giulia. 2016. Imagining Others: Social Daydreaming and the Regulation of SocioEmotional Well-being. PhD. University of Sheffield. Available at: http:/ / etheses.whiterose.ac.uk/11724 / (Accessed: 23 February 2017). 
Powell, Hilary, Morrison, Hazel, and Felicity Callard. 2018. “Wandering Minds: Tracing Inner Worlds Through a Historical-Geographical Art Installation." GeoHumanities 4(1): 132-156.

Rheinberger, Hans-Jörg. 1997. Toward a History of Epistemic Things: Synthesizing Proteins in the Test Tube. Stanford, CA: Stanford University Press.

Rosenthal, Caitlin. 2018. Accounting for Slavery: Masters and Management. Cambridge, MA: Harvard University Press.

Schüll, Natasha D., and Caitlin Zaloom. 2011. "The Shortsighted Brain: Neuroeconomics and the Governance of Choice in Time." Social Studies of Science 41(4): 515-538.

Seli, Paul, Jonathan Smallwood, James Allan Cheyne, and Daniel Smilek. 2015. "On the Relation of Mind Wandering and ADHD Symptomatology." Psychonomic Bulletin \& Review 22(3): 629-636.

Singer, Jerome L. 1975. "Navigating the Stream of Consciousness: Research in Daydreaming and Related Inner Experience." American Psychologist 30: 727-738.

Smallwood, Jonathan, and Jonathan W. Schooler. 2006 "The Restless Mind." Psychological Bulletin 132(6): 946-958.

Smallwood, Jonathan, and Jonathan W. Schooler. 2015. "The Science of Mind Wandering: Empirically Navigating the Stream of Consciousness." Annual Review of Psychology 66: 487-518.

Stawarczyk, David. 2018. "Phenomenological Properties of Mind-Wandering and Daydreaming: A Historical Overview and Functional Correlates." In The Oxford Handbook of Spontaneous Thought: Mind-Wandering, Creativity, and Dreaming, edited by Kalina Christoff and Kieran C.R. Fox, 193-214. Oxford: Oxford University Press.

Thompson Klein, Julie. 2010. "A Taxonomy of Interdisciplinarity." In The Oxford Handbook of Interdisciplinarity, edited by Robert Frodeman, Julie Thompson Klein, and Carl Mitcham, 15-30. Oxford: Oxford University Press.

Woodworth, Robert Sessions. 1899. The Accuracy of Voluntary Movement. New York and London: Macmillan.

Woolf, Virginia. 2008 [1921]. The Mark on the Wall and Other Short Fiction. Edited by David Bradshaw. Oxford: Oxford University Press.

Wordsworth, William. 1984 [1805]. The Prelude. In William Wordsworth, edited by Stephen Gill. Oxford: Oxford University Press. 